\title{
Differentiation of Capripox Viruses by Nanopore Sequencing
}

\author{
Kamal H. Eltom 1,+(D), Anna Christina Althoff ${ }^{2,+}$, Sören Hansen ${ }^{2}$, Susanne Böhlken-Fascher ${ }^{2}$, Ausama Yousif ${ }^{3} \mathbb{D}$, \\ Hussein A. El-Sheikh ${ }^{4}$, Ahmed A. ElWakeel ${ }^{5}$ (D) Mahmoud A. Elgamal $^{3}$, Hadeer M. Mossa ${ }^{6}$, \\ Emad A. Aboul-Soud ${ }^{6}$, Janika Wolff ${ }^{7}$, Christian Korthase ${ }^{7}$, Bernd Hoffmann ${ }^{7}$ (D), Nabawia M. Adam ${ }^{8}$, \\ Sanaa A. Abdelaziz ${ }^{8}$, Mohamed A. Shalaby ${ }^{3}$ and Ahmed Abd El Wahed ${ }^{2,9, *(D)}$
}

1 Unit of Animal Health and Safety of Animal Products, Institute for Studies and Promotion of Animal Exports, University of Khartoum, Shambat 13314, Khartoum North, Sudan; kamal@uofk.edu

2 Division of Microbiology and Animal Hygiene, University of Goettingen, D-37077 Goettingen, Germany; Anna.Althoff@wlv.de (A.C.A.); hansensoer@gmail.com (S.H.); sboelkenfascher@uni-goettingen.de (S.B.-F.)

3 Department of Virology, Faculty of Veterinary Medicine, Cairo University, Giza 12211, Egypt; ausama_yousif@cu.edu.eg (A.Y.); mhmoudelgaml@yahoo.com (M.A.E.); mshalaby43@gmail.com (M.A.S.)

4 Department of Infectious Diseases, Faculty of Veterinary Medicine, Zagazig University, Zagazig 44519, Egypt; husseinelsheikhvet@gmail.com

5 Department of Epidemiology, Veterinary Medicine Directorate, General Organization of Veterinary Services, Benha 13511, Egypt; ahmedabdelhaleem946@yahoo.com

6 Department of Poxvirus Vaccines, Veterinary Serum and Vaccine Research Institute, Abbasia, Cairo 11517, Egypt; hadeervsvri@gmail.com (H.M.M.); emadaboelsouad@gmail.com (E.A.A.-S.)

7 Institute of Diagnostic Virology, Friedrich-Loeffler-Institut, Federal Research Institute for Animal Health, Südufer 10, 17493 Greifswald-Insel Riems, Germany; janika.wolff@fli.de (J.W.); christian.korthase@fli.de (C.K.); bernd.hoffmann@fli.de (B.H.)

check for updates

Citation: Eltom, K.H.; Althoff, A.C.; Hansen, S.; Böhlken-Fascher, S.; Yousif, A.; El-Sheikh, H.A.; ElWakeel, A.A.; Elgamal, M.A.; Mossa, H.M.; Aboul-Soud, E.A.; et al. Differentiation of Capripox Viruses by Nanopore Sequencing. Vaccines 2021, 9, 351. https://doi.org/10.3390/ vaccines 9040351

Academic Editor: Steven B. Bradfute

Received: 28 February 2021

Accepted: 29 March 2021

Published: 6 April 2021

Publisher's Note: MDPI stays neutral with regard to jurisdictional claims in published maps and institutional affiliations.

Copyright: (c) 2021 by the authors. Licensee MDPI, Basel, Switzerland. This article is an open access article distributed under the terms and conditions of the Creative Commons Attribution (CC BY) license (https:/ / creativecommons.org/licenses/by/ $4.0 /)$.
8 Department of Microbiology, Faculty of Veterinary Medicine, University of Khartoum, Shambat 13314, Khartoum North, Sudan; nabawiavet02011@gmail.com (N.M.A.); sabdelaziz262@gmail.com (S.A.A.)

9 Institute of Animal Hygiene and Veterinary Public Health, Faculty of Veterinary Medicine, University of Leipzig, An den Tierkliniken 43, D-04103 Leipzig, Germany

* Correspondence: abdelwahed@gwdg.de; Tel.: +49-176-613-603-25

+ Contributed equally.

Abstract: The genus capripoxvirus (CaPV), family Poxviridae, includes three virus species: goatpox virus (GPV), sheeppox virus (SPV) and lumpy skin disease virus (LSDV). CaPV causes disease outbreaks with consequent economic losses in Africa and the Middle East. LSDV has recently spread to Southeast Europe. As CaPVs share 96-97\% genetic similarity along the length of the entire genome and are difficult to distinguish using serological assays, simple, reliable and fast methods for diagnosis and species differentiation are crucial in cases of disease outbreak. The present study aimed to develop a field-applicable CaPV differentiation method. Nanopore technology was used for whole genome sequencing. A local database of complete CaPV genomes and partial sequences of three genes (RPO30, P32 and GPCR) was established for offline Basic Local Alignment Search Tool (BLAST). Specificities of $98.04 \%$ in whole genome and $97.86 \%$ in RPO30 gene runs were obtained among the three virus species, while other databases were less specific. The total run time was shortened to approximately $2 \mathrm{~h}$. Functionality of the developed procedure was proved by samples with high host background sequences. Reliable differentiation options for the quality and capacity of hardware, and sample quality of suspected cases, were derived from these findings. The whole workflow can be performed rapidly with a mobile suitcase laboratory and mini-computer, allowing application at the point-of-need with limited resource settings.

Keywords: lumpy skin disease; capripox virus; nanopore sequencing

\section{Introduction}

The genus capripoxvirus (CaPV), family Poxviridae, is composed of the three highly contagious virus species: (1) lumpy skin disease virus (LSDV), affecting mainly cattle; 
(2) goatpox virus (GPV), affecting goats; and (3) sheeppox virus (SPV), affecting sheep [1] $\mathrm{CaPV}$ s are endemic in the African continent, and LSDV has spread to Russia and Southeast Europe over the past few years [2,3]. However, recent reports from the Balkan region showed a decrease of $95 \%$ in outbreak numbers from 2016 to 2017 and a stop of spread within affected countries after vaccination [4]. In the Middle East, ring vaccinations have been established in $10 \mathrm{~km}$ radius zones around outbreak spots in Iraq and Egypt [3,5] to control the spread of the virus.

The mechanical transmission by vectors is likely to facilitate the rapid propagation of LSDV, while SPV and GPV are transmitted mainly by direct contact [2]. Biting and blood-sucking insects, such as stable flies, mosquitoes and many tick species, are reportedly involved in transmission by feeding on livestock and changing hosts frequently [6-10].

Although the severity of the diseases varies among affected animal breeds, considerable losses are mostly provoked by direct mortality, drop in milk production, emaciation, secondary infections, medication costs and trade restrictions [3,11,12]. An Ethiopian survey of 243 herds revealed a median economic loss of USD 1176 at herd level due to LSDV outbreaks, whereas a survey of 80 Indian farms affected by SPV and GPV indicated average annual income losses of $30-40 \%[12,13]$. The tendency of spreading to virus-free countries and the high economic losses in affected herds have raised interest in the topic of disease control. Development and quality assurance of vaccines and epidemiological investigations are of high priority to decrease outbreak numbers and prevent further spread to disease-free countries; therefore, accurate and reliable differentiation methods are required $[4,14,15]$.

The genetic similarity is around $96-97 \%$ within the genus $\mathrm{CaPV}$ and, therefore, the virus species cannot be distinguished using traditional molecular assays [16]. However, crossinfections and immunities have been observed despite usual host preferences [11,14,17]. For example, Isiolo and Kedong GPV strains are capable of infecting sheep, goats and cattle [18]. Nonetheless, reports of LSDV infecting sheep, or SPV and GPV infecting cattle, have not been recorded so far [19].

Many CaPV isolates turned out to be geographically adapted and divergent in host preference. Therefore, differentiation among field strains is gaining more importance in order to identify the exact cause of an outbreak, especially in virus-free countries [20]. Various conventional, real-time and restriction fragment length polymorphism- polymerase chain reaction (PCR) assays targeting RPO30, P32 and GPCR genes were developed [21-25]. Yet, PCR suffers from error rates, eventually causing lower specificity when working with rising sequence lengths. This in turn might lead to misdiagnosis, especially in the differentiation of highly similar CaPVs.

The most specific method for virus identification is sequencing. Nonetheless, published protocols still depend on the amplification of target genes via PCR, followed by amplicon sequencing $[26,27]$. Moreover, PCR requires sophisticated technology for accurate temperature control, devices of large size and heavy weight and, sometimes, complex and long protocols for library preparation. Thus, well-equipped central laboratories of high monetary value are still indispensable at the present point in time. Next-generation sequencing technologies like Ion Torrent and Illumina have been established for efficient whole genome analysis [28-30]. However, these methods rely on long procedures for sample preparation, preamplification using PCR, cumbersome workflow and massive investment in hard- and software systems, which limit the implementation of these technologies in low- and middle-income countries [31]. A promising method to evade these requirements is Nanopore sequencing, developed by Oxford Nanopore Technologies (Oxford, UK). For the procedure, a specially tailored, quick library preparation kit is available. The protocol involves the use of transposome complexes that are contained in reagents [32]. These ensure the cleavage of the DNA and attachment of barcoded transposase adapters. With the addition of sequencing adapters, better threadability of the DNA is ensured for entering the nanopore. This sequencing technology makes use of a protein nanopore embedded in a membrane which is set under voltage. As DNA passes through the pore, individual changes in ionic current are measured to identify the single nucleotides. This method can 
be performed by the MinION (Oxford Nanopore Technologies), a pocket-sized portable device of less than $100 \mathrm{~g}$, with an integrated flow cell. Its handiness and light weight allow sequencing at the point of need, providing direct translation of current measurements to nucleotide sequences via USB to a laptop. In this way, sequences of long read lengths can be generated in real-time and analysed immediately [33,34]. The procedure can be implemented in a mobile suitcase laboratory that contains all tools for sample preparation. With electricity supplied by a solar panel and/or battery, there is no necessity for any further infrastructure [35].

In the present study, we established a Nanopore sequencing method applicable for differentiating CaPVs in the field. A rapid barcoding protocol was carried out for library preparation, along with offline BLAST for analysis.

\section{Materials and Methods}

\subsection{Viral DNA}

DNA samples in cell culture of LSDV Neethling vaccine strain V100, SPPV strain V104 and GTPV strain V103 were provided by the Friedrich-Loeffler-Institut, Greifswald-Insel Riems, Germany. Full details about the used strains has been published previously [36,37].

\subsection{Sample Preparation and Extraction}

DNA was extracted from viral cell cultures using the QIAamp DNA Blood Mini Kit (QIAGEN, Hilden, Germany) as indicated in the manufacturer's instructions. The DNA quantity was measured by Nanodrop ND-1000 spectrometer (Thermo Scientific, Waltham, MA, USA).

\subsection{Library Preparation and Sequencing}

For library preparation, the SQK-RBK004 kit and protocol for rapid barcoding (Oxford Nanopore Technologies, Oxford, UK) were used as recommended by the manufacturer. Briefly, barcoding was performed by mixing $7.5 \mu \mathrm{L}$ containing a minimum of $400 \mathrm{ng}$ template DNA together with $2.5 \mu \mathrm{L}$ Fragmentation Mix. In this step, cleavage of the DNA template and attachment of the barcoded transposase adapters to the DNA is accomplished by transposome complexes stored in the Fragmentation Mix [26]. Samples were barcoded in the following order: barcodes 1 and 2, LSDV; 3 and 4, GPV; 5 and 6, SPV. The samples were pooled afterwards and mixed at equal volumes after applying AMPure XP beads (Beckman Coulter, Brea, CA, USA) for concentration. Then, $1 \mu \mathrm{L}$ of Rapid Adapter was added to the sample to enhance threading of the DNA by attachment of sequencing adapters. The FlowCell was primed by the Flush Tether and Flush Buffer containing priming mix. Finally, the library was prepared by mixing $34 \mu \mathrm{L}$ Sequencing Buffer, $25.5 \mu \mathrm{L}$ Loading Beads, $4.5 \mu \mathrm{L}$ nuclease-free water and $11 \mu \mathrm{L}$ of DNA library before being loaded to the MinION Flow Cell 9.4, which was fitted on the MinION device (Oxford Nanopore Technologies, Oxford, UK), which was, in turn, connected to a laptop. The sequencing run was initiated using MinKNOW software (Oxford Nanopore Technologies) in the laptop. Sequence data produced from $5 \mathrm{~min}$ up to $12 \mathrm{~h}$ were saved as FAST5 files on the laptop; processing to FASTQ format and separation into barcodes were accomplished by the MinKNOW.

\subsection{Offline Database and Data Processing}

The software GENEIOUS 9.1.6 (Biomatter Ltd., Auckland, New Zealand) was used for establishing the local database and further analysis using offline BLAST. Nucleotide sequences of CaPVs were downloaded from GenBank of the National Centre for Biotechnology Information (NCBI) of the United States (https://www.ncbi.nlm.nih.gov/, accessed on 24 February 2021) and stored in libraries for offline use following a filtration by deleting sequences lower than $400 \mathrm{bp}$ (full list of sequences is available online: https:/ / doi.org/10.5281/zenodo.4559911, accessed on 24 February 2021).

The first database included various whole genome sequences of the three CaPVs. Out of these, a complete LSDV genome sequence was then sectioned into thirty, fifteen and 
ten regions of lengths 5, 10 and $15 \mathrm{kbp}$, respectively, which were extracted and used as additional databases. Furthermore, numerous virus-specific sequences of the genes RPO30, P32 and GPCR, which had been used for CaPVs differentiation in former studies $[23,25]$, were retrieved from the NCBI database. A multiple alignment was run for the sequences of each gene. Subsequently, using the single-nucleotide polymorphism (SNP) detection tool, the sequences were examined in depth to identify regions with high occurrence of SNPs. The longest possible sequence of the identified region was extracted from suitable gene sequences of each virus. Thus, three virus specific extractions of each gene were used to set up the databases.

Offline BLAST of all databases was conducted for each barcode by the application of the MEGABLAST algorithm with an E-value of $10^{-100}$ and word size of 28 . Results were displayed as query-centric alignment with a maximum of one hit per read. Specificities for the offline databases were concluded by the number of hits that were species-wise aligned correctly according to the viral origin of the barcoded reads, divided by the overall number of hits in the BLAST.

Online investigation was carried out using the What's In My Pot (WIMP) tool of the EPI2ME desktop application of Oxford Nanopore Technologies. Average hits of each barcode were calculated by dividing the number of correctly identified sequences by the total number of identifications including all CaPV species.

The total sequence run was $12 \mathrm{~h}$. In order to determine the shortest sequencing time needed to collect enough data to differentiate between CaPVs, offline BLAST on sequence files starting 5 min were analyzed.

\subsection{Influence of Background}

Pooled samples from endemic regions in Egypt and Sudan were used to test the influence of the background on the test performance: Egypt \#1, pooled scabs from LSDV infected cattle; Egypt \#2, pooled LSDV cultivated lab strain with cellular background; Egypt \#3, a mixture of LSDV and SPV field strains; Sudan \#1 and \#2, suspected LSDV infection. All samples except Sudan \#1 and \#2 were confirmed to contain CaPV using molecular assay as described previously [38]. The threshold time is around $6 \mathrm{~min}$ in recombinase polymerase amplification assay.

\section{Results}

By sequencing of LSDV, GPV, SPV in duplicates, a total number of 376,812 sequence files were processed to FASTQ format and further analyzed in GENEIOUS and EPI2Me. After filtration (omitting sequences $<400$ bases), 287,110 reads were categorized into barcodes. Application of "map to reference" in GENEIOUS identified between $2.9 \%$ and $8.85 \%$ of the reads as CaPV sequences, depending on the barcoded sample (Figure 1). Barcode \#5 was excluded as the number of reads were very low, mostly because of failure of binding of the assigned barcode during library preparation (full sequences are available online: https: / / doi.org/10.5281/ zenodo.4559911, accessed on 24 February 2021).

Offline BLAST specificities of 5, 10 and $15 \mathrm{kbp}$ genome regions, whole genome, RPO30, P32 and GPCR genes databases were calculated by dividing the number of hits that correctly aligned by the total number of hits (results are summarized in Figure 2). Whole genome database showed the best average specificity of $98.04 \%$. Investigations utilizing the 15 , 10 and $5 \mathrm{kbp}$ genome regions revealed average pairwise identities ranging from $88.26 \%$ to $89.04 \%$ for the three viruses. In the gene databases, average specificities were $97.86 \%$, $84.34 \%$ and $65.56 \%$ for RPO30, P32 and GPCR genes, respectively, while the online tool, WIMP (EPI2ME), showed an average of $84.48 \%$ of the reads mapped correctly to their respective virus species. 


\section{In total 376,812 sequence files}

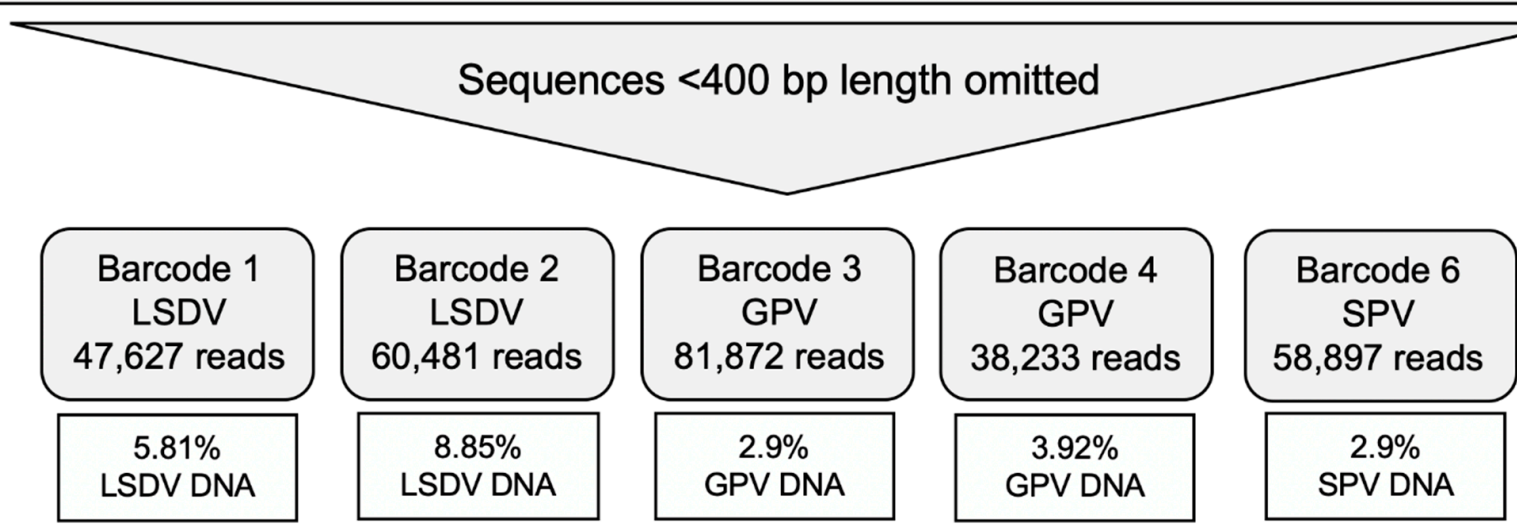

Figure 1. Filtration, classification and viral DNA amount of barcoded sequence files.

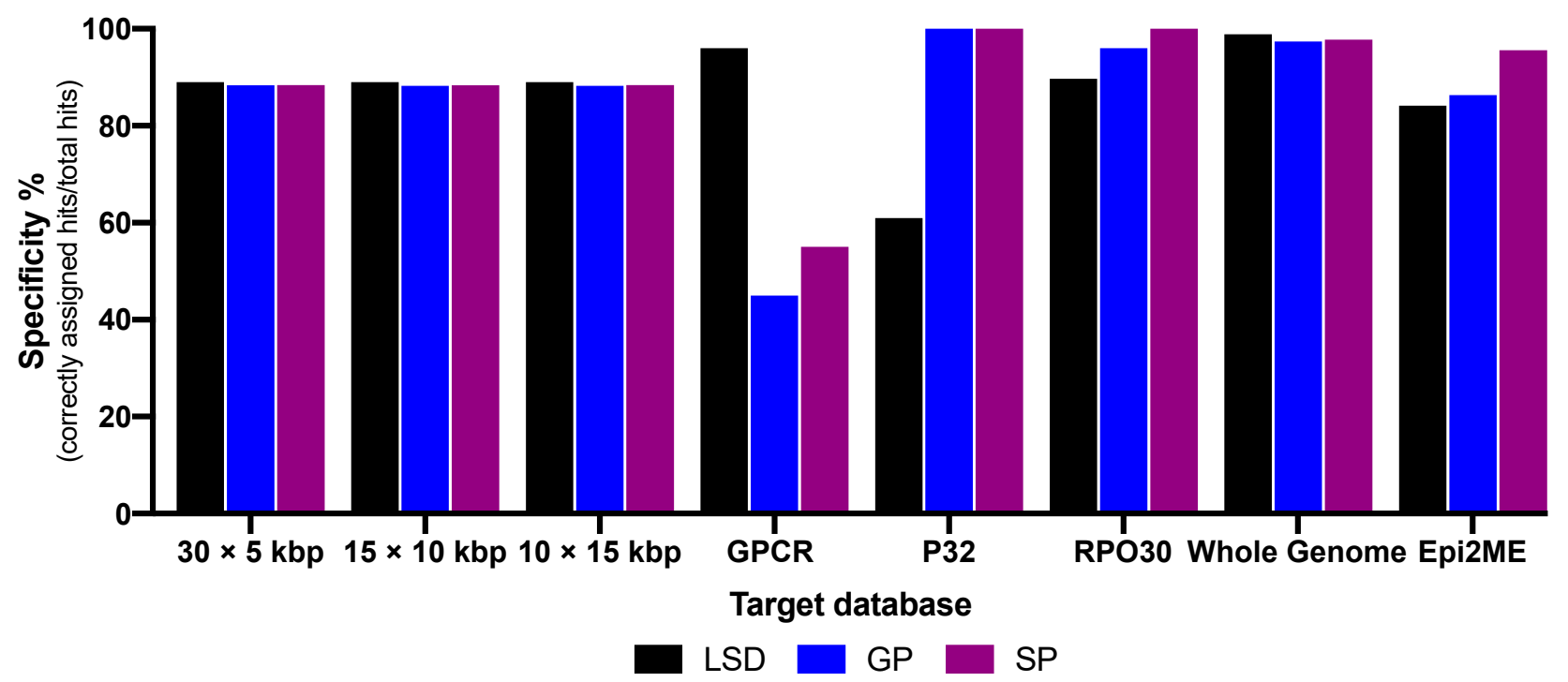

Figure 2. Average specificities of various offline Basic Local Alignment Search Tool (BLAST) and online EPI2ME databases.

While the overall workflow had been initially conducted within $22 \mathrm{~h}$ (Table 1), it was functional when the sequencing time was reduced from $12 \mathrm{~h}$ to $25 \mathrm{~min}$; the resulting total workflow became $2 \mathrm{~h}$ and 5 min (Table 2).

Table 1. Speed of the workflow.

\begin{tabular}{|c|c|c|c|}
\hline \multirow{2}{*}{ Step } & \multicolumn{2}{|c|}{ Protocol Time } & \multirow{2}{*}{ Kit/Program } \\
\hline & Short & Long & \\
\hline Extraction & \multicolumn{2}{|c|}{$1 \mathrm{~h}$} & QIAamp DNA Blood Mini Kit \\
\hline Library Preparation & \multicolumn{2}{|c|}{$20 \mathrm{~min}$} & Rapid Barcoding Sequencing Kit \\
\hline Sequencing & $25 \mathrm{~min}$ & $12 \mathrm{~h}$ & MinION Flow Cell 9.4 \\
\hline Data Processing & $15 \mathrm{~min}$ & $8 \mathrm{~h}$ & MinKNOW \\
\hline Analysis & $5 \mathrm{~min}$ & $30 \mathrm{~min}$ & GENEIOUS \\
\hline Total & $2 \mathrm{~h} 5 \mathrm{~min}$ & $22 \mathrm{~h}$ & \\
\hline
\end{tabular}


Table 2. Comparison between the specificities of short ( $2 \mathrm{~h})$ and long ( $22 \mathrm{~h})$ sequencing protocols.

\begin{tabular}{|c|c|c|c|c|c|c|c|c|c|c|}
\hline \multirow{2}{*}{$\begin{array}{l}\text { Barcode } \\
\text { Run time }\end{array}$} & \multicolumn{2}{|c|}{$\begin{array}{c}1 \\
\text { (LSD) }\end{array}$} & \multicolumn{2}{|c|}{$\begin{array}{c}2 \\
\text { (LSD) }\end{array}$} & \multicolumn{2}{|c|}{$\begin{array}{c}3 \\
(G P)\end{array}$} & \multicolumn{2}{|c|}{$\begin{array}{c}4 \\
(G P)\end{array}$} & \multicolumn{2}{|c|}{$\begin{array}{c}6 \\
\text { (SP) }\end{array}$} \\
\hline & $\begin{array}{l}\text { Short } \\
\text { ( 2 h) }\end{array}$ & $\begin{array}{l}\text { Long } \\
(22 \text { h) }\end{array}$ & $\begin{array}{l}\text { Short } \\
(\sim 2 \text { h) }\end{array}$ & $\begin{array}{l}\text { Long } \\
(22 \mathrm{~h})\end{array}$ & $\begin{array}{l}\text { Short } \\
(\sim 2 \text { h) }\end{array}$ & $\begin{array}{l}\text { Long } \\
(22 \text { h) }\end{array}$ & $\begin{array}{l}\text { Short } \\
(\sim 2 \text { h) }\end{array}$ & $\begin{array}{l}\text { Long } \\
(22 \text { h) }\end{array}$ & $\begin{array}{l}\text { Short } \\
\text { ( 2 h) }\end{array}$ & $\begin{array}{l}\text { Long } \\
(22 \mathrm{~h})\end{array}$ \\
\hline Total number of Reads & 1854 & 47,627 & 2174 & 60,481 & 3104 & 81,872 & 2158 & 38,233 & 2202 & 58,897 \\
\hline $\begin{array}{c}\text { Specificity in \% } \\
\text { Whole genome BLAST }\end{array}$ & 98.68 & 98.8 & 98.8 & 98.8 & 96.69 & 96.7 & 97.79 & 98 & 97.59 & 97.7 \\
\hline
\end{tabular}

Pooled samples from endemic regions were used for validating the influence of the background on the nanopore sequencing and database performances (Table 3). Databases of whole genome and RPO30 gene as well as WIMP were applied for data analysis as they have shown the best specificity (Figure 2). The runs of the whole genome database identified Egypt \#1 and \#2 as LSDV, whereas Egypt \#3 showed hits of LSDV and SPV. RPO30 BLAST did not show results for Egypt \#1 and \#2, while Egypt \#3 revealed one SPV hit. WIMP mapped all Egypt samples as LSDV, with increasing amounts of Egypt \#3 reads mapped as SPV. The software did not identify reads of the samples from Sudan as CaPV. Both offline BLAST based on the whole genome and the WIMP were the most accurate databases in the presence of host background.

Table 3. Results of validation runs using samples from Egypt and Sudan, presented as percentage of mappings in offline BLAST and WIMP. Total number of correctly assigned hits is around $1 \%$ of the total number of reads. Most of the reads are background of host genome. The percentages in the table represent the specificities of the BLAST.

\begin{tabular}{ccccc}
\hline $\begin{array}{c}\text { Sample } \\
\text { (Total Reads) }\end{array}$ & Egypt \#1 & $\begin{array}{c}\text { Egypt \#2 } \\
\mathbf{( 1 0 , 6 5 2 )}\end{array}$ & $\begin{array}{c}\text { Egypt \#3 } \\
\mathbf{( 1 1 , 2 6 8 )}\end{array}$ & $\begin{array}{c}\text { Sudan \#1 } \\
\mathbf{( 3 0 , 5 2 9 )}\end{array}$ \\
\hline \multirow{2}{*}{ Whole genome } & $95.08 \%$ LSDV & $90.67 \%$ LSDV & $74.19 \%$ LSDV & \\
RPO30 & No results & No results & $17.2 \%$ SPV & No results \\
WIMP & $95.88 \%$ LSDV & SPV (1 Hit) & $77.58 \%$ LSDV & \\
& & & $19.84 \%$ LSDV & \\
\hline
\end{tabular}

\section{Discussion}

We were able to develop a highly specific differentiation method for the species of $\mathrm{CaPV}$ genus using Nanopore sequencing. The sequencing run was performed using a portable MinION device, while further differentiation was facilitated by offline local BLAST. Additionally, the WIMP online tool was tested.

The data analysis protocol is simple: the collected reads can be transferred to GENEIOUS software, which enables a simple handling in further data processing. All libraries needed for offline BLAST can be created by accessing the nucleotide database in the GenBank. The procedure can be prepared in advance by downloading CaPV sequences to GENEIOUS and creating databases of whole genome. In this way, point-of-need virus differentiation is enabled.

CaPV genome is comprised of two noncoding identical inverted regions of tandem sequences (inverted terminal repeats) on the leftmost and rightmost sides bound to the central coding region. As mapped in Figure 3, the central genomic region contains mostly genes that encode replicative mechanisms and virion morphogenesis components. This region is enclosed by terminal genomic regions coding virulence and host range genes, for the most part $[15,16]$. Local BLAST was applied using whole genome sequences. Notably, all whole genome runs showed high specificities with an average of $98.04 \%$ of the sequences aligned correctly regarding the reads' virus species. In the perspective of former studies that investigated genes in online sequence analysis [26,27], the use of whole genome sequences for offline analysis and differentiation is a novelty. This approach is 
eminently precise by aligning the $150 \mathrm{kbp}$ long $\mathrm{CaPV}$ genome, yet it is adaptable to the variability of different isolates.

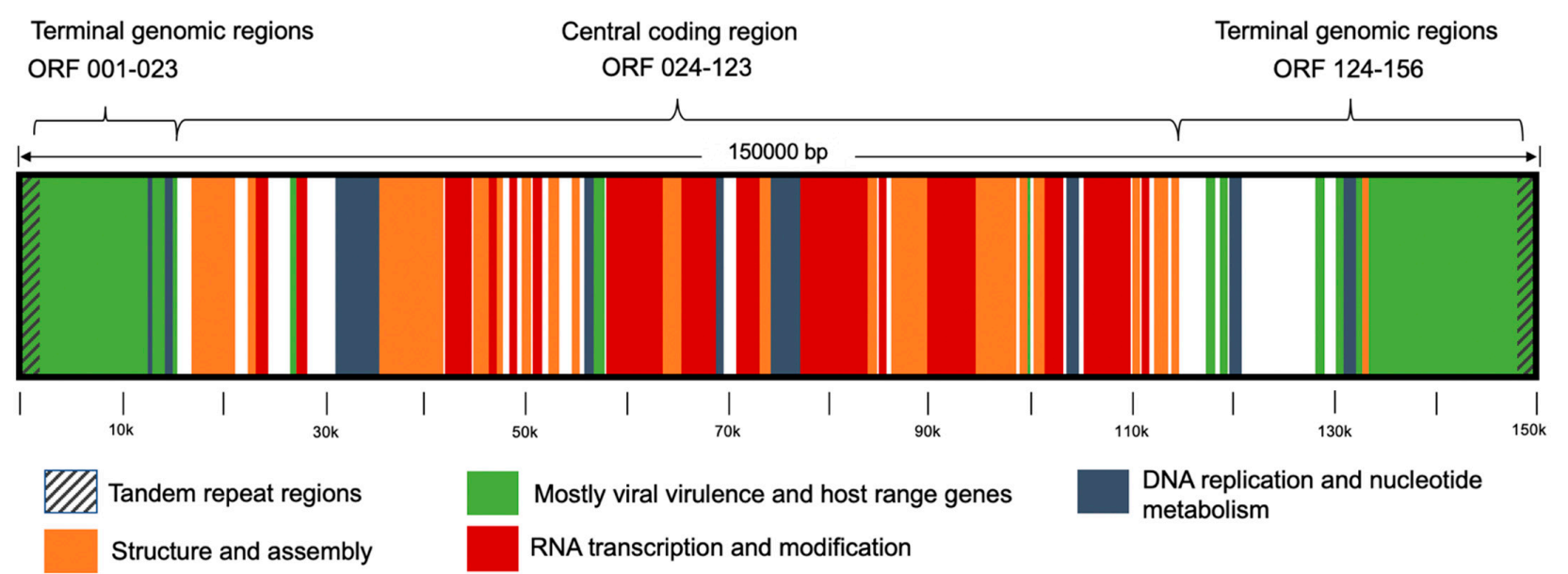

Figure 3. Capripox virus genome organisation, modified from Tulman et al., 2001.

In order to detect genome regions that distinguish the virus species, multiple libraries of 15,10 and $5 \mathrm{kbp}$ long sequences taken from LSDV genome were established. For comparison, pairwise identities of the BLAST were examined. No significant divergences between the pairwise identities of LSDV and those of GPV and SPV were found. Therefore, none of the regions showed evidence of further genetic difference suitable for virus differentiation.

For smaller database sizes, RPO30 gene proved high universal effectiveness with an average specificity of $97.86 \%$. However, P32 and GPCR genes were not consistent in functionality. While P32 showed outstanding specificities of 100\% in GPV and SPV, it had divergent results of $60.8 \%$ in LSDV. In contrast, GPCR gene was highly specific for LSDV, but of low specificity for GPV (39.7\%) and SPV (55.8\%). Positively correlated results of GPV and SPV in contrast to those of LSDV may most likely be affected by the genetic difference of the hosts, with adaption of GPV and SPV to animals of the caprine species and LSDV to bovines. These observations coincide with previous studies that found some genes in LSDV were disrupted in both GPV and SPV [16]. However, the difference in suitability might also be reasoned in gene function and structure (Figure $4 \mathrm{~A}-\mathrm{C}$ ), as average specificity depends on gene size and number of SNPs. Thus, due to the low number of SNPs in RPO30 gene, divergences had a greater effect on the distinguishability of the viruses, whereas higher numbers of SNPs on the other genes caused a higher probability of being cancelled out by each other. Consequently, this resulted in more incorrect alignments and confusion in the differentiation. Additional approaches of combining different gene sequences in one database led to immense drops in specificity (data are shown in Supplementary File \#1).

When the WIMP tool included in the desktop application EPI2ME of Oxford Nanopore Technologies was further tested as an online alternative, an average of $84.48 \%$ of correctly mapped sequences was obtained. Nevertheless, all barcodes have been identified successfully, proving reliability of the service. Moreover, the application provides a user-friendly interface with a more rapid result report than local BLAST. Considering the practicability in point-of-need implementation, WIMP depends on a stable internet connection, which is not always available, especially in rural areas. On the contrary, offline BLAST offered virus differentiation without this requirement. For validation of the used methods, whole genome and RPO30 databases were applied in further local BLAST using LSDV positive samples from Egypt and samples of LSDV suspects from the Sudan. While no hits were reported from both Sudan samples in all BLAST runs, samples \#1 and \#2 from Egypt were identified as LSDV, and sample \#3 as both LSDV and SPV by the whole genome run. RPO30 database reported no hits in Egypt \#1 and \#2, and again SPV as identification of Egypt \#3. Subsequently, WIMP tool was applied, which did not show CaPV-related results in Sudan 
\#1 and \#2. In fact, the previous results of local BLAST of Egypt samples corresponded to those of the WIMP analysis, showing major mapping to LSDV in Egypt \#1 and \#2, followed by high amounts of LSDV and increased mapping numbers of SPV in Egypt \#3.

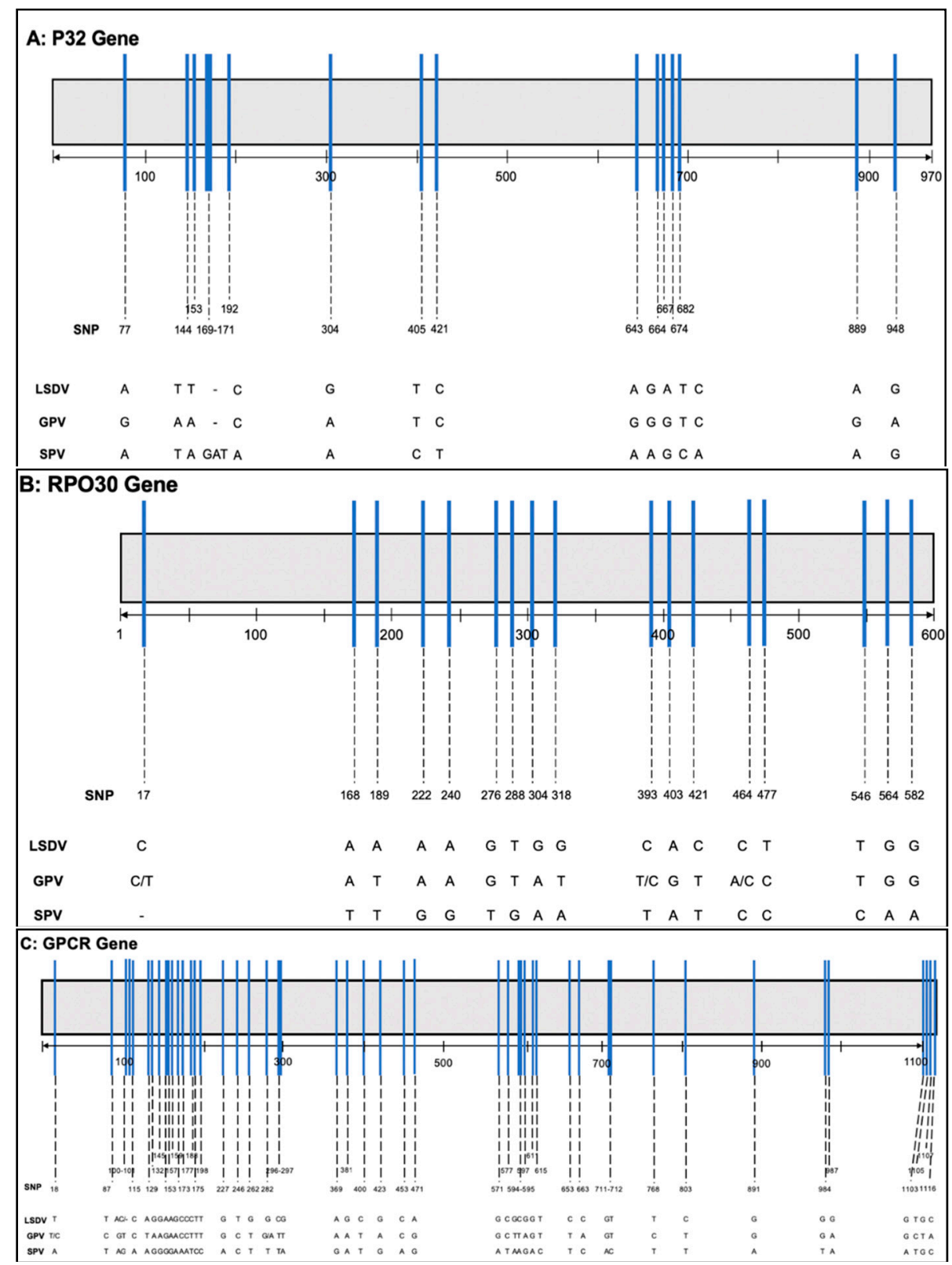

Figure 4. Single-nucleotide polymorphism (SNP) mapped to (A) P32 gene, (B) RPO30 gene and (C) GPCR gene. The single nucleotides of each position are shown below for LSDV, GPV and SPV.

The local BLAST proved to be suitable for differentiation. Based on the obtained results, the whole genome BLAST database offers highly specific results among all CaPV species and is recommended to be performed using outstanding hardware facilities. In case of limited access to whole genome data, gene libraries provide high specificities and smaller size of the database. Depending on the case, genes can be applied interchangeably: in suspicion of LSDV, a combination of RPO30 and GPCR is recommended. For suspicion of GPV and SPV, RPO30 and P32 should be applied.

Furthermore, the online application WIMP can be used for accelerated result report. Although it performed successfully in this study, validation by offline BLAST is still advis- 
able. However, despite its fast result report, the tool is still dependent on the availability of internet access.

Advanced infrastructure is a required component in the current state of diagnostics. Previously published protocols for $\mathrm{CaPV}$ differentiation that involved sequencing had been performed by target gene amplification using PCR, followed by cumbersome sequencing protocols and analysis by online algorithms [26,27]. Areas affected by CaPV outbreaks, however, are mostly lacking well-equipped, costly laboratories and steady internet connection. We have overcome these needs through the combination of Nanopore sequencing and offline BLAST. The use of a suitcase laboratory allows on-site sample preparation; with a size of $56 \times 45.5 \times 26.5 \mathrm{~cm}$, it stores all of the tools and equipment required for the protocol [35]. The suitcase is shock absorbent and waterproof, and can be supplied with electricity by a solar panel. In this way, it is safe to transport and implement the equipment in low resource settings. Compared to PCR-based techniques, the usability of a suitcase system is superior due to its handiness and lower costs [35]. With sequencing conducted by a MinION device connected to a laptop, and sequence analysis performed using an offline algorithm, all requirements for CaPV differentiation are portable and field applicable, providing fast results. Furthermore, the online application WIMP can provide clues to the existence of other pathogens that may be contributing to observed disease conditions in sampled animals. Therefore, our method has the potential for versatile use in humble conditions and consequently enables accelerated diagnosis at the outbreak site.

\section{Conclusions}

In conclusion, we have accomplished the development of a fast and highly specific method for differentiation of CaPVs. The method is easy to replicate in laboratories or in a mobile suitcase laboratory for direct application in the field. Nevertheless, other clinically relevant issues must be addressed in future studies. This includes, but is not limited to, identification of clinical cases due to vaccination [39], differentiation between virulent and attenuated vaccine strains [40] and detection of the recombination events between vaccine and wild-type LSDV strains [41].

Supplementary Materials: The following are available online at https://www.mdpi.com/2076-3 93X/9/4/351/s1. Supplementary file \#1 contains the tables of the offline BLAST specificities of combining various genes.

Author Contributions: Conceptualization, K.H.E., S.H., M.A.S. and A.A.E.W.; methodology, K.H.E., A.C.A., S.B.-F., A.Y., A.A.E.W.; software, K.H.E., A.C.A., S.H., A.A.E.W.; validation, K.H.E., A.C.A., S.H., S.B.-F., A.Y., H.A.E.-S., A.A.E., M.A.E., H.M.M., E.A.A.-S., J.W., C.K., B.H., N.M.A., S.A.A., M.A.S., A.A.E.W.; formal analysis, K.H.E., A.C.A., S.H., S.B.-F., A.Y., H.A.E.-S., A.A.E., M.A.E., H.M.M., E.A.A.-S., J.W., C.K., B.H., N.M.A., S.A.A., M.A.S., A.A.E.W.; investigation, K.H.E., A.C.A., S.H., S.B.-F., A.Y., H.A.E.-S., A.A.E., M.A.E., H.M.M., E.A.A.-S., J.W., C.K., B.H., N.M.A., S.A.A., M.A.S., A.A.E.W.; resources, A.Y., H.A.E.-S., A.A.E., M.A.E., H.M.M., E.A.A.-S., J.W., C.K., B.H., N.M.A., S.A.A., M.A.S., A.A.E.W.; visualization, K.H.E., A.C.A., A.A.E.W.; data curation, K.H.E., A.C.A., S.H., S.B.-F., A.Y., A.A.E.W.; writing—original draft preparation, K.H.E., A.C.A., A.A.E.W.; writing-review and editing, K.H.E., A.C.A., S.H., S.B.-F., A.Y., H.A.E.-S., A.A.E., M.A.E., H.M.M., E.A.A.-S., J.W., C.K., B.H., N.M.A., S.A.A., M.A.S., A.A.E.W.; visualization, K.H.E., A.C.A., A.A.E.W. supervision, A.Y., B.H., M.A.S., A.A.E.W.; project administration, K.H.E., A.A.E.W.; funding acquisition, A.A.E.W. All authors have read and agreed to the published version of the manuscript.

Funding: No specific funding was obtained to conduct the study.

Institutional Review Board Statement: Not applicable.

Informed Consent Statement: Not applicable.

Data Availability Statement: All data are presented in the study and the full sequences as well as BLAST database available online: https:/ / doi.org/10.5281/zenodo.4559911 Accessed on 24 February 2021.

Acknowledgments: We acknowledge the support of the Open Access Publication Funds of the University of Goettingen, Germany. 
Conflicts of Interest: The authors declare no conflict of interest.

\section{References}

1. Friedrich-Loeffler-Institut, F.L.I. National Reference Laboratory for Sheep and Goat Pox and National Reference Laboratory for Lumpy-skin-Disease (LSD). Available online: https:/ / www.fli.de/en/institutes/institute-of-diagnostic-virology-ivd/referencelaboratories/nrl-for-sheep-and-goat-pox/ (accessed on 28 August 2020).

2. World Organisation for Animal Health. Lumpy Skin Disease (LSD). Available online: https://www.oie.int/fileadmin/Home/ eng/Media_Center/docs/pdf/Posters/EN_Poster_LSD_2016.pdf (accessed on 28 August 2020).

3. Al-Salihi, K.A.; Hassan, I.Q. Lumpy Skin Disease in Iraq: Study of the Disease Emergence. Transbound Emerg. Dis. 2015, 62, 457-462. [CrossRef] [PubMed]

4. European Food Safety Authority. Scientific report on lumpy skin disease II. Data collection and analysis. EFSA J. 2018, 16, 5176.

5. Services, G.O.F.V. Overview on Vector-borne diseases in Egypt. Available online: https://rr-africa.oie.int/wp-content/uploads/ 2020/12/15-egypt-overview-on-vector-borne-diseases-in-egypt.pdf (accessed on 8 January 2021).

6. Kitching, R.P.; Mellor, P.S. Insect transmission of capripoxvirus. Res. Vet. Sci 1986, 40, 255-258. [CrossRef]

7. Kahana-Sutin, E.; Klement, E.; Lensky, I.; Gottlieb, Y. High relative abundance of the stable fly Stomoxys calcitrans is associated with lumpy skin disease outbreaks in Israeli dairy farms. Med. Vet. Entomol. 2017, 31, 150-160. [CrossRef] [PubMed]

8. Chihota, C.M.; Rennie, L.F.; Kitching, R.P.; Mellor, P.S. Mechanical transmission of lumpy skin disease virus by Aedes aegypti (Diptera: Culicidae). Epidemiol. Infect. 2001, 126, 317-321. [CrossRef] [PubMed]

9. Tuppurainen, E.S.; Lubinga, J.C.; Stoltsz, W.H.; Troskie, M.; Carpenter, S.T.; Coetzer, J.A.; Venter, E.H.; Oura, C.A. Mechanical transmission of lumpy skin disease virus by Rhipicephalus appendiculatus male ticks. Epidemiol. Infect. 2013, 141, 425-430. [CrossRef]

10. Tuppurainen, E.S.; Lubinga, J.C.; Stoltsz, W.H.; Troskie, M.; Carpenter, S.T.; Coetzer, J.A.; Venter, E.H.; Oura, C.A. Evidence of vertical transmission of lumpy skin disease virus in Rhipicephalus decoloratus ticks. Ticks Tick Borne Dis. 2013, 4, 329-333. [CrossRef] [PubMed]

11. Davies, F.G. Lumpy skin disease, an African capripox virus disease of cattle. Br. Vet. J. 1991, 147, 489-503. [CrossRef]

12. Molla, W.; de Jong, M.C.M.; Gari, G.; Frankena, K. Economic impact of lumpy skin disease and cost effectiveness of vaccination for the control of outbreaks in Ethiopia. Prev. Vet. Med. 2017, 147, 100-107. [CrossRef]

13. Garner, M.G.; Sawarkar, S.D.; Brett, E.K.; Edwards, J.R.; Kulkarni, V.B.; Boyle, D.B.; Singh, S.N. The extent and impact of sheep pox and goat pox in the state of Maharashtra, India. Trop Anim. Health Prod. 2000, 32, 205-223. [CrossRef] [PubMed]

14. Carn, V.M. Control of capripoxvirus infections. Vaccine 1993, 11, 1275-1279. [CrossRef]

15. Tulman, E.R.; Afonso, C.L.; Lu, Z.; Zsak, L.; Kutish, G.F.; Rock, D.L. Genome of lumpy skin disease virus. J. Virol. 2001, 75, 7122-7130. [CrossRef]

16. Tulman, E.R.; Afonso, C.L.; Lu, Z.; Zsak, L.; Sur, J.H.; Sandybaev, N.T.; Kerembekova, U.Z.; Zaitsev, V.L.; Kutish, G.F.; Rock, D.L. The genomes of sheeppox and goatpox viruses. J. Virol. 2002, 76, 6054-6061. [CrossRef] [PubMed]

17. Capstick, P.B. Lumpy skin disease-experimental infection. Bul. Epiz Dis. Afr. 1959, 7, 51-62.

18. Tuppurainen, E.S.; Pearson, C.R.; Bachanek-Bankowska, K.; Knowles, N.J.; Amareen, S.; Frost, L.; Henstock, M.R.; Lamien, C.E.; Diallo, A.; Mertens, P.P. Characterization of sheep pox virus vaccine for cattle against lumpy skin disease virus. Antivir. Res. 2014, 109, 1-6. [CrossRef] [PubMed]

19. Tuppurainen, E.S.M.; Venter, E.H.; Shisler, J.L.; Gari, G.; Mekonnen, G.A.; Juleff, N.; Lyons, N.A.; De Clercq, K.; Upton, C.; Bowden, T.R.; et al. Review: Capripoxvirus Diseases: Current Status and Opportunities for Control. Transbound Emerg. Dis. 2017, 64, 729-745. [CrossRef] [PubMed]

20. Kitching, R.P.; Taylor, W.P. Clinical and antigenic relationship between isolates of sheep and goat pox viruses. Trop Anim. Health Prod. 1985, 17, 64-74. [CrossRef] [PubMed]

21. Santhamani, R.Y.R.; Venkatesan, G.; Shivachandra, S.B.; Pandey, A.B.; Ramakrishnan, M.A. Detection and differentiation of sheeppox virus and goatpox virus from clinical samples using $30 \mathrm{kDa}$ RNA polymerase subunit (RPO30) gene based PCR. Vet. World 2013, 6, 923-925. [CrossRef]

22. Mahmoud, M.A.; Khafagi, M.H. Detection, identification, and differentiation of sheep pox virus and goat pox virus from clinical cases in Giza Governorate, Egypt. Vet. World 2016, 9, 1445-1449. [CrossRef]

23. Orlova, E.S.; Shcherbakova, A.V.; Diev, V.I.; Zakharov, V.M. Differentiation of capripoxvirus species and strains by polymerase chain reaction. Mol. Biol. 2006, 40, 158-164. [CrossRef]

24. Lamien, C.E.; Lelenta, M.; Goger, W.; Silber, R.; Tuppurainen, E.; Matijevic, M.; Luckins, A.G.; Diallo, A. Real time PCR method for simultaneous detection, quantitation and differentiation of capripoxviruses. J. Virol. Methods 2011, 171, 134-140. [CrossRef] [PubMed]

25. Venkatesan, G.; Balamurugan, V.; Yogisharadhya, R.; Kumar, A.; Bhanuprakash, V. Differentiation of sheeppox and goatpox viruses by polymerase Chain reaction-restriction fragment length polymorphism. Virol. Sin. 2012, 27, 353-359. [CrossRef] [PubMed]

26. Hosamani, M.; Mondal, B.; Tembhurne, P.A.; Bandyopadhyay, S.K.; Singh, R.K.; Rasool, T.J. Differentiation of sheep pox and goat poxviruses by sequence analysis and PCR-RFLP of P32 gene. Virus Genes 2004, 29, 73-80. [CrossRef] [PubMed] 
27. Lamien, C.E.; Lelenta, M.; Silber, R.; Goff, C.L.; Wallace, D.; Gulyaz, V.; Tuppurainen, E.; Luckins, A.G.; Albina, E.; Diallo, A. Phylogenetic analysis of the Capripox virus RPO30 gene and its use for development of a PCR for differentiating SPPV from GTPV. In Proceedings of the FAO/IAEA International Symposium on Sustainable Improvement of Animal Production and Health, Vienna, Austria, 8-11 June 2009; pp. 323-326.

28. Agianniotaki, E.I.; Mathijs, E.; Vandenbussche, F.; Tasioudi, K.E.; Haegeman, A.; Iliadou, P.; Chaintoutis, S.C.; Dovas, C.I.; Van Borm, S.; Chondrokouki, E.D.; et al. Complete Genome Sequence of the Lumpy Skin Disease Virus Isolated from the First Reported Case in Greece. Genome Announc. 2017, 5. [CrossRef] [PubMed]

29. Biswas, S.; Noyce, R.S.; Babiuk, L.A.; Lung, O.; Bulach, D.M.; Bowden, T.R.; Boyle, D.B.; Babiuk, S.; Evans, D.H. Extended sequencing of vaccine and wild-type capripoxvirus isolates provides insights into genes modulating virulence and host range. Transbound Emerg. Dis. 2020, 67, 80-97. [CrossRef]

30. Lahens, N.F.; Ricciotti, E.; Smirnova, O.; Toorens, E.; Kim, E.J.; Baruzzo, G.; Hayer, K.E.; Ganguly, T.; Schug, J.; Grant, G.R. A comparison of Illumina and Ion Torrent sequencing platforms in the context of differential gene expression. BMC Genomics 2017, 18, 602. [CrossRef]

31. Slatko, B.E.; Gardner, A.F.; Ausubel, F.M. Overview of Next-Generation Sequencing Technologies. Curr. Protoc. Mol. Biol. 2018, 122, e59. [CrossRef]

32. Oxford-Nanopore-Technologies. Rapid Barcoding Sequencing (SQK-RBK004). Available online: https://store.nanoporetech. com/rapid-barcoding-kit.html (accessed on 30 January 2020).

33. Jain, M.; Olsen, H.E.; Paten, B.; Akeson, M. The Oxford Nanopore MinION: Delivery of nanopore sequencing to the genomics community. Genome Biol. 2016, 17, 239. [CrossRef] [PubMed]

34. Laver, T.; Harrison, J.; O’Neill, P.A.; Moore, K.; Farbos, A.; Paszkiewicz, K.; Studholme, D.J. Assessing the performance of the Oxford Nanopore Technologies MinION. Biomol. Detect. Quantif. 2015, 3, 1-8. [CrossRef]

35. Abd El Wahed, A.; Weidmann, M.; Hufert, F.T. Diagnostics-in-a-Suitcase: Development of a portable and rapid assay for the detection of the emerging avian influenza A (H7N9) virus. J. Clin. Virol. 2015, 69, 16-21. [CrossRef]

36. Moller, J.; Moritz, T.; Schlottau, K.; Krstevski, K.; Hoffmann, D.; Beer, M.; Hoffmann, B. Experimental lumpy skin disease virus infection of cattle: Comparison of a field strain and a vaccine strain. Arch. Virol. 2019, 164, 2931-2941. [CrossRef]

37. Wolff, J.; King, J.; Moritz, T.; Pohlmann, A.; Hoffmann, D.; Beer, M.; Hoffmann, B. Experimental Infection and Genetic Characterization of Two Different Capripox Virus Isolates in Small Ruminants. Viruses 2020, 12, 1098. [CrossRef]

38. Shalaby, M.A.; El-Deeb, A.; El-Tholoth, M.; Hoffmann, D.; Czerny, C.P.; Hufert, F.T.; Weidmann, M.; Abd El Wahed, A. Recombinase polymerase amplification assay for rapid detection of lumpy skin disease virus. BMC Vet. Res. 2016, 12, 244. [CrossRef] [PubMed]

39. Kononov, A.; Byadovskaya, O.; Kononova, S.; Yashin, R.; Zinyakov, N.; Mischenko, V.; Perevozchikova, N.; Sprygin, A. Detection of vaccine-like strains of lumpy skin disease virus in outbreaks in Russia. Arch. Virol. 2019, 164, 1575-1585. [CrossRef] [PubMed]

40. Menasherow, S.; Rubinstein-Giuni, M.; Kovtunenko, A.; Eyngor, Y.; Fridgut, O.; Rotenberg, D.; Khinich, Y.; Stram, Y. Development of an assay to differentiate between virulent and vaccine strains of lumpy skin disease virus (LSDV). J. Virol. Methods 2014, 199, 95-101. [CrossRef]

41. Sprygin, A.; Pestova, Y.; Bjadovskaya, O.; Prutnikov, P.; Zinyakov, N.; Kononova, S.; Ruchnova, O.; Lozovoy, D.; Chvala, I.; Kononov, A. Evidence of recombination of vaccine strains of lumpy skin disease virus with field strains, causing disease. PLoS ONE 2020, 15, e0232584. [CrossRef] [PubMed] 